\title{
DO RACISMO NA ESCOLA A UMA ESCOLA CONTRA O RACISMO: REFLEXÕES A RESPEITO DO CENÁRIO BRASILEIRO
}

\author{
Victor André Pinheiro Cantuário ${ }^{1}$ \\ Marcia Ferreira da Silva Alves ${ }^{2}$
}

\section{RESUMO}

O presente artigo tem por objetivo apresentar ponderações a respeito da maneira como o racismo evidente e manifesto em falas e comportamentos de indivíduos na sociedade brasileira contribui para a negação da humanidade e o apagamento de sujeitos em função de seu pertencimento étnico-racial, levando-se em consideração o importante papel que a escola deve desempenhar a fim de combater quaisquer formas de preconceito e discriminação, principalmente produzindo ações que se tornem eficazes já nos primeiros anos do Ensino Fundamental. Para se atingir tal objetivo, utilizou-se como metodologia a pesquisa de caráter qualitativo, com delineamento exploratório, a partir do objetivo definido, e de procedimento bibliográfico com coleta de dados em textos já publicados a respeito do tema e dispostos em materiais impressos ou em meios digitais. $\mathrm{O}$ resultado a que chega com o escrito aponta para a necessidade do fortalecimento de práticas pedagógicas e de ações de conscientização para o enfrentamento de grave problema persistente na sociedade brasileira, na qual uma parcela ainda tem insistido na via da negação do racismo e na existência de uma democracia racial. Extraindo-se por conclusão a constatação de que a escola precisa abraçar sua missão social e permitir a efetivação de políticas educacionais incisivas e que se tornem eficazes para a formação de

\footnotetext{
Doutorando do Programa de Estudos Literários (UNESP). Professor do Curso de Licenciatura em Pedagogia da Universidade Federal do Amapá, campus Santana. ORCID: https://orcid.org/0000-0002-1706-1016 E-mail: ve.cantuario@gmail.com

2 Especialista em Políticas de Igualdade Racial na Escola (UNIFAP). Graduada em Licenciatura Plena em Letras (FACULDADE MADRE TEREZA). Professora de Língua Portuguesa, Rede Pública de Ensino, Estado do Amapá. ORCID: https://orcid.org/00000003-1343-6295. E-mail: marciaegarcia@gmail.com
} 
indivíduos dispostos ao diálogo e não ao conflito que apenas alimenta o abismo de ignorância caracterizador de uma sociedade que se tem mostrado, ao menos em parte, indisposta a enfrentar e resolver seus dilemas mais agudos.

Palavras-chave: Racismo. Escola. Sociedade brasileira.

\section{FROM RACISM IN SCHOOL TO A SCHOOL AGAINST THE RACISM: CONSIDERATIONS ABOUT THE BRAZILIAN SCENE}

\section{ABSTRACT}

This article has by aim to present comprehensions about the way racism exposed and manifest em speeches and individual behaviors in Brazilian society contributes to the denial of humanity and the obliteration of some persons by their ethnic recognition, in considering the essential role of the school in this matter struggling any kind of prejudice and discrimination, mostly producing actions with substantial effectiveness mainly in the Elementary School. To achieve that objective, it was made use as methodology the research of qualitative type and exploratory basis with bibliographic procedure of data, accessing texts about the subject in books or digital media. The result of the discussion shows that it is needed the strengthening of pedagogic practices and actions of conscientization to face this chronic problem still existent in the Brazilian society, in which some individuals have insisted in the denial of the racism and in the reality of some kind of racial democracy. Considering by conclusion that it is through the school, assuming its social goal, the consolidation of educational and strength policies will be realized in the process of building persons opened to the dialogue but not to the conflict who only feeds the abyss of ignorance that it is an strong attribute of a society that has sadly revealed itself, at least some individuals, unable to face its major dilemmas.

Keywords: Racism. Elementary School. Brazilian Society. 


\section{DEL RACISMO EN LA ESCUELA A UNA ESCUELA CONTRA EL RACISMO: REFLEXIONES A RESPECTO DEL PANORAMA BRASILEÑO}

\section{RESUMEN}

Este articulo tiene por objetivo presentar algunas consideraciones a respeto de la manera como el racismo claro y manifiesto en hablas y comportamientos de los individuos en la sociedad brasileña ha contribuido para la negación de la humanidad y el apagamiento de los sujetos en razón de su identificación étnico-racial, sabiéndose que la escuela tiene inevitablemente un papel muy importante a desempeñar en el combate a todas las formas de prejuicio y discriminación, principalmente produciendo acciones que sean eficaces ya en los primeros años de la enseñanza elemental. Para llegarse al cumplimiento de lo objetivo descrito se hace aplicación de metodología con investigación cualitativa, de carácter exploratorio, a partir de dicho objetivo, y de revisión bibliográfica acerca del problema con acceso a textos disponibles en línea o libros. El resultado alcanzado con este escrito muestra que es fundamental avanzar en el fortalecimiento de prácticas pedagógicas y de acciones para la tomada de conciencia mirando el enfrentamiento de uno grave problema mucho presente en la sociedad brasileña, en la cual una parte aún se posiciona por la negación del racismo y por la creencia en una democracia racial. Por lo tanto, una de las conclusiones es la constatación de que en Brasil la escuela necesita abrazar su tarea social y permitir la realización de fuertes políticas educacionales que se tornen caminos viables para la formación de individuos dispuestos al dialogo y jamás elijan el conflicto que sólo alimenta el abismo de ignorancia como marca de una sociedad que se tiene hecho ver, en parte, poco lista a enfrentar y solucionar sus dilemas más severos.

Palabras clave: Racismo. Enseñanza Elemental. Sociedad Brasileña. 


\section{INTRODUÇÃO}

O entendimento histórico do que é o racismo no Brasil tem demonstrado que sobre o assunto o consenso não é algo compartilhado, pois parte de quem discute a questão, por longo tempo, defendeu que não havia, principalmente, após a abolição da escravidão, em fins do século XIX, tal problema na realidade do país, escolhendo, portanto, a via da negação como caminho a seguir, sustentar e defender, compreendendo que aquele evento, em particular, contribuiu para que se estabelecesse o que se identificou na sociedade brasileira a partir da expressão "democracia racial" (SKIDMORE, 1976), e que os casos de preconceito racial, à vista da lei, não passavam de contravenção, isto é, crime de menor gravidade; ao menos esse foi o entendimento legal segundo a Lei Afonso Arinos, de 1951, e que perdurou até a década de 1980 (JORDÃO, 2019).

Outra parte, no entanto, não apenas manteve-se fiel à denúncia de sua existência, isto é, à denúncia secular do racismo e de seus efeitos estigmatizantes para a sociedade e para os indivíduos suas vítimas, como passou, pela via da afirmação e da exposição de seus condicionantes, a desconstruir veementemente a farsa orquestrada e mantida sob o rótulo de democracia racial (FERNANDES, 1972).

Ocorre que a denúncia adquiriu corpo e alcançou os espaços jurídicos, materializando-se tanto na letra da lei, conforme se pode observar na Constituição Federal de 1988, quanto nos dispositivos legais específicos, como a Lei antirracismo de 1989, ou a Lei n. 10.639 de 2003, esta última direcionada ao meio educacional, e a Lei n. 12.228 de 2010, que instituiu o Estatuto da Igualdade Racial.

Importante destacar que apesar desses avanços e conquistas legais e apesar do rigor da lei, a diminuição dos casos de racismo ainda é um horizonte que se visa de longe a ser alcançado, pois como salienta Vieira (apud JORDÃO, 2019):

Demorou a haver o entendimento de que era necessário um dispositivo legal para coibir essas práticas. O Brasil deixou de ser escravocrata há 130 anos e a lei está completando 30. Ou seja, há uma lacuna de 100 anos [...] O ganho mais importante 
dela é o pedagógico. Existe o mito da democracia racial, de que nós não somos um país racista, de que o racismo é velado. Para os negros, ele nunca foi velado, porque acontece diuturnamente. A lei mostrou que o Brasil é, sim, um país racista e precisa de ações efetivas para lidar com isso.

Portanto, se é perceptível que o combate ao preconceito, à discriminação e ao racismo ${ }^{3}$ no Brasil, nas últimas décadas, tem mostrado pontos positivos, é necessário que haja maior envolvimento de todos os segmentos da sociedade civil e instituições públicas e privadas para que práticas como aquelas sejam coibidas e punidas devidamente nos termos da lei, e seus perpetradores tomem consciência do quão nocivo são, para quem é vítima, os efeitos de tais atos.

À luz dessas considerações é que surge como problema a ser vislumbrado a seguinte questão: De que maneira a escola, como ambiente formal de educação, local em que ocorre o processo de ensino-aprendizagem, pode contribuir eficazmente para o combate ao racismo e, por consequência, para a valorização e o respeito do pertencimento étnico-racial das crianças negras?

Isto quer dizer que a escola é uma das instituições sociais que deve servir a esse propósito, como espaço de convivência e socialização por excelência, desenvolvendo pedagogias de combate ao racismo que somente serão eficazes se ela, isto é, todos os seus atores, aceitar a tarefa em prol da construção de uma sociedade justa

\footnotetext{
${ }^{3}$ Assumindo a tarefa de apresentar definições para se trabalhar no combate ao preconceito, à discriminação e ao racismo, Silva (2001, p. 75-76) propõe que o primeiro "é basicamente uma atitude negativa (é necessário que haja algum referente positivo para comparação) com relação a um grupo ou pessoa, baseando-se num processo de comparação social em que o grupo da pessoa preconceituosa é considerado um ponto positivo de referência"; quanto à discriminação, entende que "é a manifestação comportamental do preconceito, ou seja, é a materialização da crença racista em atitudes que efetivamente limitam ou impedem o desenvolvimento humano pleno das pessoas pertencentes ao grupo discriminado e mantêm os privilégios dos membros do grupo discriminador à custa do prejuízo dos participantes do grupo dos discriminados"; ao passo que por racismo entende serem ações que tendem a "negar a humanidade das pessoas negras, comparando-as por meio de seus atributos físicos a coisas, doenças e animais." A ponto de se naturalizarem tanto esses comportamentos negativos que "todo o mundo passa a achar que isso é engraçado, louvável e quem se indigna é 'neurótico/a'."
} 
e igualitária, na qual a diferença seja celebrada, a alteridade promovida e toda e qualquer forma de discriminação seja rechaçada, pois, do contrário, continuar-se-á diante de um cenário sustentado não pelo fomento ao conhecimento, mas pela sua ausência. "O que não permite ao indivíduo negro ser reconhecido pelo que é, mas sim falsamente reconhecido" (CAVALLEIRO, 2012, p. 23).

E é baseado nesses indicativos que surge o interesse em pesquisar o tema "valorização da criança negra" a partir da constatação de serem frequentes e estarem se naturalizando os casos de racismo na escola brasileira, dando-se ênfase aos primeiros anos do Ensino Fundamental, momento de ingresso da criança no sistema formal de educação no país e, igualmente, momento oportuno para que aluno e escola possam lidar com questões complexas como o preconceito.

Nessa trilha de discussão, optou-se por realizar pesquisa de caráter qualitativo, e como instrumento e procedimento técnico de coleta de dados o bibliográfico, pois fez-se uso de textos já publicados sobre o assunto e dispostos em material impresso, de acervo particular e pertencente ao acervo da Biblioteca Central do Campus Marco Zero da Universidade Federal do Amapá, ou acessado digitalmente em sítios de busca ou repositórios de arquivos, como o Scielo, conforme caracterização de pesquisa proposta por Prodanov e Freitas (2013), para a construção do referencial sobre as categorias de análise "valorização da criança negra" e "racismo na escola".

Ademais, em função do objetivo mencionado, optou-se por pesquisa exploratória, pois para compreender o fenômeno discutido, qual seja, o racismo na escola como obstáculo ao reconhecimento da criança negra, sua valorização e seu pertencimento étnico-racial, é necessário demonstrar as suas características e condicionantes (FIGUEIREDO, 2008).

Amparado nessas considerações, o trabalho foi pensado e estruturado em três momentos que, dadas as necessidades da discussão viável do tema, estão interligados de maneira a comporem um conjunto harmônico, coeso e coerente de exposição de ideias, portanto, em inter-relação.

No primeiro, tratar-se-á de expor algumas observações a respeito da existência do racismo, contrariando a lógica do "todos 
iguais perante a lei", que serve de sustento à ideia da democracia racial. No segundo, discutir-se-á a maneira como crianças ingressantes no Ensino Fundamental, ao trazerem consigo preconceitos a respeito de si e dos outros, encontram na escola um espaço não de fomento à diversidade e ao respeito, mas de reforço a práticas de racismo e discriminação; e, baseado nessa perspectiva, na terceira parte, serão comentados alguns caminhos para constituir a escola em um local de ação e transformação social e de produção de pedagogias de combate a toda forma de preconceito e discriminação.

\section{RACISMO À BRASILEIRA: quando a afirmação reside na negação}

Ainda que sejam fortes ou chocantes, por isso não deixam de corresponder à realidade as constatações cotidianas de que o Brasil é um país racista, mas que parece tentar esconder sob a máscara da cordialidade e dos sorrisos festivos essa série de fatos produzida e reproduzida nos diálogos paralelos travados socialmente seja no transporte urbano, nos jogos de futebol ou nas rodas de conversas entre amigos, por exemplo; nos comerciais e programas televisivos ou outdoors, que privilegiam o fenótipo branco sobre os demais; nas redes sociais, espaços que vêm sendo utilizados para a proliferação de uma cultura do ódio e da intolerância; nos personagens da literatura infantil, geralmente brancos e quando não o são, descritos como exóticos ou incivilizados (RODRIGUES; AQUINO, 2010).

Além disso, no não reconhecimento político dos sujeitos sociais negros que ainda são minoria nas esferas do poder público; nos ambientes formais de educação em que ainda persistem visões de ensino desprivilegiando as diferenças ou não visando a construção de práticas pedagógicas as quais deem, de fato, visibilidade a todos os alunos, levando em consideração seu saber e cultura prévios, suas individualidades, seu pertencimento étnico-racial, apesar de o texto da LDBEN n. 9.394/1996 determinar em seu art. $3^{\circ}$, incisos de I ao XII, que esses elementos estão entre os princípios orientadores do ensino no país (BRASIL, 2017). 
Semelhante postura também se reproduz no ambiente familiar quando falas ou comportamentos de seus membros demonstram a negação de seu ser em privilégio do outro, estabelecendo-se essa negação como expressão de uma violência que além de psicológica, efetiva-se verbal e fisicamente, visto que, como diz Souza (1983, p. 7): "tenta-se metamorfosear o corpo presente, atual, de modo penoso e caricato. São os 'pregadores de roupa' destinados a afilar o nariz ou os produtos químicos usados para alisar o 'cabelo ruim'."

Essas tentativas grosseiras de negação, no entanto, já são episódio frequente na história do país, pois como bem pontua Skidmore (1976, p. 12), antes de 1888, ano marco da abolição da escravidão, a intelectualidade brasileira, isto é, a elite composta pela minoria educada e com forte tendência à imitação, imitando as modas de época, em todas as áreas, advindas da Europa ou da América do Norte; imitando no vestir, no falar, na literatura, na política; aderindo às correntes de pensamento criadas lá fora e querendo, a todo custo, fazê-las vingar por aqui, essa intelectualidade, quer dizer, essa elite, "pouca atenção dava ao problema da raça em si, bem como à relação entre as características raciais do país e seu desenvolvimento futuro."

A constatação do historiador norte-americano, como brasilianista, pode, para alguns, soar estranha e descabida, por se tratar de olhar estrangeiro sobre problema interno, mas é uma perspectiva que não apenas a maioria da população desconhece ou simplesmente ignora conhecer, em pleno século XXI, como outros bem preferem argumentar, a fim de continuar acreditando que são mais evoluídos ou civilizados que indivíduos de outras épocas, preferindo também acreditar que a abolição deu fim à escravidão, todos passaram a ser iguais perante a lei e o que resta é narrativa de ficção.

Mas os fatos históricos caminham bem na direção contrária dessas crenças, pois mesmo os defensores da abolição da escravatura - esta vista como anacronismo que ameaçava o país e seu ideal de desenvolvimento e civilização, dado o seu caráter tardio, em razão de ter sido o Brasil um dos últimos a abolir a escravidão, quando comparado com países europeus e com os Estados Unidos da 
América - como Joaquim Nabuco, Rui Barbosa e Euclides da Cunha, ícones do pensamento nacional, "eram contrários á (sic) escravidão, mas imbuídos do racismo e da inferioridade inata dos negros." (SILVA, 2007, p. 95)

Por esse motivo, tais figuras tornaram-se vigorosos defensores de ideologias do branqueamento, fazendo coro, com outras importantes personalidades da intelectualidade brasileira como Afrânio Peixoto e Silvio Romero, à defesa do branqueamento como solução para um "problema", visto que, nas palavras do primeiro desses dois, "trezentos anos talvez, levaremos para mudar de alma e alvejar a pele, e se não brancos, ao menos disfarçados, perderemos o caráter mestiço" (SILVA, 2007, p. 96).

Em resumo, diz Cavalleiro (2012, p. 23-24), refletindo duramente sobre essas e outras afirmativas, tais formas de preconceito são evidenciadas e inevitavelmente se fazem presentes "na sociedade brasileira, no cotidiano dos indivíduos, e é altamente prejudicial para a população negra, tanto nas relações sociais (família, escola, bairro, trabalho etc.) quanto nos meios de comunicação."

Como se vê, ocultar algo manifesto, preferindo-se o caminho da negação em vez do enfrentamento, tem sido a opção de parte da população brasileira e de alguns de seus segmentos; na contramão dessa postura, tanto a outra parte da sociedade civil, nada satisfeita com evidências e ocorrências de racismo, quanto o Governo Federal têm se mostrado contrários à qualquer forma de expressão ou ação discriminatória e preconceituosa, buscando através de campanhas e, no caso do segundo, de atos legais conscientizar o cidadão de que estará incorrendo em conduta criminosa se insistir em agir de maneira a ferir direitos assegurados na Constituição Federal, como os que se apoiam no fundamento da dignidade da pessoa humana, art. $1^{\circ}$, inciso III, art. $3^{\circ}$, inciso IV; ou no direito à vida, art. $5^{\circ}$, caput, incisos XLI e XLII (BRASIL, 2018a).

Ao seu turno, a educação, como parte integrante da estrutura governamental e direito garantido e assegurado à população em conformidade com 0 art. $6^{\circ}$ da CF (BRASIL, 2018a), foi contemplada primeiro em 2003 com a promulgação da Lei n. 10.639, cujo texto propunha alteração na redação da LDBEN, a fim de incluir os arts. 26A, 79-A (Vetado) e 79-B, que tratam da inclusão, respectivamente, no 
currículo dos estabelecimentos de ensino fundamental e médio, públicos e privados, de conteúdos referentes ao "estudo da história e cultura afro-brasileira e indígena", e no calendário escolar do dia 20 de novembro, decretado "Dia da Consciência Negra" (BRASIL, 2017, p. 21); no ano seguinte, com a publicação das Diretrizes Curriculares Nacionais para a Educação das Relações Étnico-raciais e para o Ensino de História e Cultura Afro-brasileira e Africana (DCNs da ERER ${ }^{4}$ ), cujo intuito relaciona-se com a implementação da lei de 2003, bem como servir de eixo orientador para a

formulação de projetos empenhados na valorização da história e cultura dos afro-brasileiros e dos africanos, assim como comprometidos com a de educação de relações étnico-raciais positivas, a que tais conteúdos devem conduzir (BRASIL, 2004, p. 9)

Por fim, chegou-se à publicação da Lei n. 12.228 de 2010, a qual instituiu o Estatuto da Igualdade Racial visando, a partir do escrito em seu art. $1^{\circ}$, caput,

garantir à população negra a efetivação da igualdade de oportunidades, a defesa dos direitos étnicos individuais, coletivos e difusos e o combate à discriminação e às demais formas de intolerância étnica (BRASIL, 2015, p. 13).

Apesar de todos esses esforços voltados para o combate social e institucional ${ }^{5}$ a tais práticas desumanas e depreciativas, ao que tudo indica, ainda não se conseguiu dar resolução adequada a esse problema, isto é, ainda não se pôs um

${ }^{4}$ De acordo com Carth (2019), "ERER foi uma sigla atribuída por participantes do Movimento Negro em um evento na Região Norte promovido pela Coordenação-Geral de Diversidade da SECAD em 2008 chamado Diálogos Regionais."

${ }^{5}$ Pettigrew (apud CAVALLEIRO, 2012, p. 22) informa haver uma diferença entre ambos os tipos de racismo individual e institucional. "O primeiro inclui atitudes preconceituosas e comportamentos discriminatórios. Contrastando com essa idéia, porém, o racismo institucional engendra um conjunto de arranjos institucionais que restringem a participação de um determinado grupo racial (no nosso caso, o grupo de negros). Esse tipo de racismo está ligado à estrutura da sociedade e não aos seus indivíduos." 
um ponto final na questão racial, uma vez que ainda não [se] conseguiu convencer as mentes mais esclarecidas da sociedade brasileira [...]. Além disso, o conhecimento que circula os espaços acadêmicos [e de ensino, em geral] continua a ter um caráter monocultural (RODRIGUES; AQUINO, 2010, p. 4).

Um contraponto mais recente à essa insistência no particular, no monocultural, na prevalência de uma matriz cultural, de um capital intelectual sobre os demais, quer dizer, na reprodução, com consequências graves, de ideologias do branqueamento, aliada aos dispositivos legais citados anteriormente é a Base Nacional Comum Curricular (BNCC), quando, ao menos textualmente, reafirma a existência da diversidade cultural e a necessidade de um diálogo pluriétnico, consciente de que

por si só não alterará o quadro de desigualdade ainda presente na Educação Básica do Brasil, mas é essencial para que a mudança tenha início porque, além dos currículos, influenciará a formação inicial e continuada dos educadores, a produção de materiais didáticos, as matrizes de avaliações e os exames nacionais que serão revistos à luz do texto homologado da Base (BRASIL, 2018b, p. 5).

Entretanto, ainda que se apresente como documento normativo

que define o conjunto orgânico e progressivo de aprendizagens essenciais que todos os alunos devem desenvolver ao longo das etapas e modalidades da Educação Básica", nas escolas brasileiras, públicas e privadas, com intenção de "superar a fragmentação das políticas educacionais. (BRASIL, 2018b, p. 7, destaque do autor)

O cenário real e cotidiano do ensino e da educação no país ainda se encontra bem distante desse idealmente descrito e delineado. 
Por isso, além de mobilizar-se para enfrentar social e legalmente ${ }^{6}$ o racismo que se quer negar ou ocultar atrás de sutilezas, falas ou comportamentos que pretendem velar a sua concretude ou amenizar seus impactos, é necessário perceber que os efeitos da discriminação dirigida a outras pessoas em função de questões como a cor da pele ou a aparência física, isto é, aos aspectos fenotípicos, findam por produzir estereótipos que, consequentemente, serão responsáveis pela propagação do preconceito, dando origem aos estigmas que se traduzem naquelas marcas atribuídas a um indivíduo de maneira negativa e discriminatória. $E$ isto é o que a sociedade brasileira tem feito frequentemente ao enxergar o sujeito negro como inferior não apenas social como culturalmente; não apenas política como intelectualmente; não apenas econômica como profissionalmente impingindo-lhe marcas que se têm encontrado forte resistência para desfazer.

Como bem dizem as DCNs da ERER (BRASIL, 2004, p. 14-15):

Combater o racismo, trabalhar pelo fim da desigualdade social e racial, empreender reeducação das relações étnico-raciais não são tarefas exclusivas da escola. As formas de discriminação de qualquer natureza não têm o seu nascedouro na escola, porém o racismo, as desigualdades e discriminações correntes na sociedade perpassam por ali. Para que as instituições de ensino desempenhem a contento o papel de educar, é necessário que se constituam em espaço democrático de produção e divulgação de conhecimentos e de posturas que visam a uma sociedade justa.

Assim, desconstruir estigmas para possibilitar a socialização de indivíduos outrora estigmatizados é um processo social que a escola, entre outras instituições sociais, por exemplo, pode provocar de maneira alinhada com os dispositivos legais supracitados, mas,

\footnotetext{
${ }^{6}$ Somada aos arts. da CF citados, como instrumento legal de combate ao racismo está a Lei n. 7.716 de 1989, conhecida como Lei Antirracismo, que completou 30 anos em janeiro último, cuja redação sofreu alterações com a publicação da Lei do Estatuto da Igualdade Racial (BRASIL, 2015).
} 
principalmente, com o respeito à condição do outro que somente é diferente, porém, jamais inferior, e essa diferença é, com toda certeza, positiva para a geração e o fortalecimento de práticas sociais cada vez mais eficazes à promoção da alteridade e na direção contrária de uma certa visão unilateral a respeito da questão étnico-racial ainda muito presente e prevalente em todos os setores profissionais públicos ou privados e esferas de sociabilidade do país.

O que quer dizer, em termos mais patentes, que o Brasil não apenas é um país racista como parte de sua população tem se dedicado e esforçado para negar direitos já contemplados em lei, creditando a questões como as cotas ou a leis específicas uma tal vitimização da população negra que se em nada é inferior a outros grupos étnicos existentes no país, defendem esses indivíduos, de modo algum teria necessidade de qualquer tratamento especial perante a lei e as instituições formais que constituem a administração pública e jurídica nacionais.

\section{O RACISMO VAI À ESCOLA: ou quais preconceitos os alunos trazem consigo?}

Anualmente, no Brasil, milhares de crianças ingressam na educação básica ${ }^{7}$ em escolas públicas ou privadas, levando-se em consideração a idade regular de quatro a cinco anos determinada por lei tanto na CF, art. 208, quanto na LDBEN, art. 30, inciso II, para a entrada na Educação infantil, pré-escola; e de seis anos para o início do Ensino Fundamental, art. 32 (BRASIL, 2017, 2018a).

No entanto, uma observação é necessária, em conformidade com o que já se expôs em momento anterior: nenhuma dessas crianças adentra no espaço escolar, no ambiente formal destinado ao ensino-aprendizagem, vazia, oca ou como sendo uma folha em

\footnotetext{
${ }^{7}$ Dados do Censo Escolar de 2018 ilustram essa afirmativa apontando que neste ano "foram registradas 48,5 milhões de matrículas nas 181,9 mil escolas de educação básica brasileiras [...]. As matrículas da educação básica são encontradas majoritariamente na área urbana (88,7\%). Na rede privada, 99,0\% das matrículas estão em escolas urbanas. $\mathrm{Na}$ rede pública, as escolas municipais são as que apresentam a maior proporção de matrículas em escolas rurais (19,5\%), seguida das escolas estaduais, com 5,2\% das matrículas" (INEP, 2019, p. 2).
} 
branco na qual os professores irão dar início ao registro das vivências somente a partir do instante em que a criança agregar o rótulo de aluno à sua existência social.

Pelo contrário, e seguindo a trilha das teorias construtivistas ${ }^{8}$, todas essas crianças, agora inscritas no papel de sujeitos da educação, como alunos, possuem um saber e experiências extraescolares que devem ser reconhecidas, respeitadas e valorizadas, art. $3^{\circ}$, inciso $\mathrm{X}$ da LDBEN (BRASIL, 2017); e conhecimentos prévios que devem ser utilizados em conjunto com aqueles a serem apreendidos e desenvolvidos na escola, como propõe a BNCC (BRASIL, 2018b); pois, passa-se a saber, a partir de estudos da psicologia do desenvolvimento humano, que a criança, já ambientada ao espaço escolar, isto é, na idade dos seis anos, avança em termos qualitativos em direção ao amadurecimento da socialização.

E em decorrência disso, a respeito do desenvolvimento intelectual,

a visão egocêntrica dos anos pré-escolares cede lugar a outros pontos de vista. Suas percepções não mais dominam o pensamento. $O$ pensamento operacional concreto torna o escolar capaz de raciocinar de forma dedutiva. Ele vai da premissa às conclusões de modo lógico, mas limitado a eventos observáveis [...] O escolar passa a estabelecer relações e comparações entre os fatos [...]. Além disso, adquire o conceito de reversibilidade, isto é, a idéia de que a situação original pode ser restaurada. Assim, pode pensar em uma mesma ação em direção contrária (RIBEIRO et al., 2009, p. 83-84).

No tocante à linguagem, eixo do desenvolvimento humano fundamental para a formação de conceitos, para a expressão de

\footnotetext{
${ }^{8}$ Cujas bases estão associadas inevitavelmente às obras de Piaget, Vigotski, Wallon. "Cada um à sua maneira, os três se opuseram a teorias que defendiam que o conhecimento é inato e a outras convencidas de que o que sabemos é absorvido apenas do ambiente onde vivemos". Outros teóricos como Ausubel, Ferreiro, Lerner e Kamii contribuíram para revigorar o movimento construtivista (SCACHETTI; CAMILO, 2015).
} 
pensamentos, para a consolidação de visões de mundo, humano e sociedade,

Com 6 anos a criança possui um vocabulário de 2.500 a 3.000 palavras. Seu discurso é fluente, claro e foneticamente correto. Ela entende sinônimos e consegue dar explicações às ocorrências. Expressase com sentenças de 5 a 6 palavras e apresenta sintaxe gramatical correta.

O escolar é capaz de relatar um fato na ordem cronológica dos acontecimentos. Sente prazer de contar histórias, em geral de fatos ocorridos na escola ou nos grupos de amigos. Passa a se interessar por leitura e descobre que há um "mundo" a ser conhecido por meio dos livros (RIBEIRO et al., 2009, p. 89).

Outros aspectos igualmente são expostos pelos autores, como o desenvolvimento psicossocial, a relação da criança escolarizada com um ou mais grupos de amigos, a sua imagem corporal, o desenvolvimento da moralidade, a disciplina, a espiritualização e a sexualidade.

Pelo exposto, nota-se que ao ingressar na escola as crianças já trazem consigo visões de mundo e de sociedade que poderão permanecer ou ser desconstruídas positiva ou negativamente, dependendo da maneira como na sua prática pedagógica o professor, em particular, e a escola, em geral, dediquem-se a um trabalho de conscientização e não de sustentação de estereótipos, estigmas ou ações de discriminação e políticas de inferiorização, indiferença ao preconceito e ao racismo; preferindo silenciar-se diante disso que abraçar a tarefa de combatê-los.

O silêncio utilizado como estratégia para se evitar o combate ao racismo e a quaisquer formas de discriminação e preconceito, bem como a tomada de consciência e a convivência harmônica entre os indivíduos, consequentemente, em vez de ser elemento motivador, torna-se obstáculo em razão dos efeitos que traz consigo.

Os problemas se acumulam: ausência de informação, aliada a um pretenso conhecimento, resulta no silêncio diante das diferenças étnicas. [...] 
Assim, vivendo numa sociedade com uma democracia racial de fachada, destituída de qualquer preocupação com a convivência multiétnica, as crianças aprendem as diferenças, no espaço escolar, de forma bastante preconceituosa (CAVALLEIRO, 2012, p. 58).

Dessa forma, em vez de ser espaço de modificação e transformação social, a escola transforma-se em local de proliferação e propagação de preconceitos, caso mantenha-se fiel ao silenciamento em vez da exposição de situações que dia a dia ou tomam as páginas dos jornais, da mídia, de modo mais ampliado, os registros policiais, ou se reduzem a algumas falas tímidas e desajeitadas advindas de sujeitos que se sentem forçados a negar seu pertencimento étnico-racial percebendo-se, por isso, menores que outros não apenas tratados distintamente como vistos e reconhecidos de maneira superior.

O que se questiona nesse contexto é que essa experiência é imposta diante de uma sociedade em que ser branco(a) é a "norma", ou seja, a noção hegemonicamente estabelecida e legitimada indica que a brancura é associada a uma situação de privilégio que desacredita na presença da austeridade de sua posição e, por isso mesmo, é incapaz de compreender a experiência do "outro" (ROSSATO; GESSER, 2001, p. 11).

Esse outro, que está constantemente à frente do eu, se inscrito em um pertencimento que se distancie da norma mencionada, há de sofrer, em represália à sua condição humana, os danos por parte de quem socialmente aprendeu a vê-lo como menor em todos os sentidos.

$\mathrm{Na}$ escola, os exemplos se multiplicam. Em quase todas as famílias brasileiras negras ou assim identificadas ouvem-se histórias e narrativas de acontecimentos envolvendo casos de discriminação, muitos deles ocorrendo na própria sala de aula - espaço originalmente destinado ao esclarecimento, ao processo de ensinoaprendizagem -, na qual se relatam situações em que o professor agente qualificado pelo Estado, através de curso de formação 
superior, com certificação cuja validade se reconhece em todo o território nacional, para mediar aquele processo e o qual deveria se dedicar a práticas de construção e reforço da igualdade e respeito à diferença - personifica o papel, por vezes, de primeiro agente de discriminação com o qual o aluno entrará em contato; outras vezes sendo uma extensão daquilo com o que o indivíduo se já deparou em casa ou na rua.

E qual lugar, à luz dessa descrição complexa e desses comportamentos profissionais, é reservado aos alunos não brancos? Esses são, em determinadas situações

\begin{abstract}
considerados alunos "atrasados" porque com frequência apresentavam dificuldades de aprendizagem, e muito pouco ou nada era feito para ajudá-los na superação de suas dificuldades. Em contrapartida, os alunos de pele branca em geral eram considerados bons alunos - alunos nota " $A$ " e, por consequência, eram presenteados no final do ano letivo de acordo com o ranking de primeiro, segundo e terceiro lugar da classe (ROSSATO; GESSER, 2001, p. 19, grifo dos autores).
\end{abstract}

Explicar para uma criança, apesar de seu desenvolvimento intelectual e linguístico permiti-la compreender isso, que não é boa o bastante, que não é um aluno destaque, aluno nota " $\mathrm{A}$ ", que não está nem entre os três primeiros em rendimento escolar e associar isso à sua cor de pele, ao seu pertencimento étnico-racial é uma das maiores demonstrações de violência, nada simbólica, praticada contra indivíduos socialmente.

Configurando-se a escola, recorde-se Dubet (2003), nessa perspectiva, como uma das maiores causadoras e produtora de exclusão e de preconceitos, principalmente quando toma para si, isto é, abraça ideologias e visões de humano e sociedade que em nada contribuem para o esclarecimento, por serem vazias de conteúdo e apoiadas em interpretações distorcidas de teorias científicas, mas para a persistência na ignorância.

Diante dessa análise, o racismo mais tóxico é aquele internalizado e institucionalizado, proveniente de 
pessoas com senso de moralidade, bemintencionadas e pessoas religiosas. A pessoa que sofre o racismo não causa sua condição [como tentam fazer crer alguns "educadores", ideólogos e políticos]. O que acontece na verdade é que os agentes na posição de dominação e poder subjulgam (sic) outros menos afortunados (ROSSATO; GESSER, 2001, p. 25).

E essa constatação é feita em todos os continentes, em vários países, inclusive naqueles cujo elemento étnico original nem era caucasiano como os EUA e o Brasil, e sim vermelho e nativo ameríndio, respectivamente; ou, por outro lado, esse elemento étnico original era negro como no caso da Austrália e do continente africano.

Locais esses de onde emanaram tendências de dominação que se espalharam mundo afora ou se fortaleceram consoante o grupo político que estivesse no poder, pois pode-se afirmar que a classe política constitui-se em um grupo em muito responsável pela legitimação de visões racistas nas sociedades em que atuam, creditando aos seus eleitores a tomada de decisões quanto a assuntos que dizem respeito à garantia ou não de direitos às populações historicamente vítimas de algumas forma de violência ou destituição de sua humanidade dada a cor de sua pele, sua sexualidade, religiosidade etc.

Voltando-se à escola, e ficando evidenciado que brancos e não brancos não compartilham das mesmas condições de acesso e permanência nos ambientes formais de ensino, estatais ou privados, observa-se que a educação ofertada aos alunos não brancos, ainda que se tenha conhecimento de que ambos os públicos convivem na mesma sala de aula, é inegavelmente diferente: o que os alunos não brancos por muito tempo estudaram em determinadas disciplinas como língua portuguesa, história e geografia, por exemplo, foram os registros oficiais baseados nas visões de mundo de correto e civilizado dos brancos.

Somente há pouco mais de uma década tendo sido dado fundamento legal para a inclusão de outras matrizes culturais como a afro-brasileira e a indígena, através da Lei n. 10.639/03, no conteúdo 
programático, de acordo com o artigo 26-A da LDBEN (BRASIL, 2017); contudo, no tocante ao aspecto linguístico, a contribuição ou o aprendizado de línguas provenientes dessas duas tradições ainda não contam com espaço nem de oferta nos currículos escolares, resumindo-se, no estudo daquelas disciplinas citadas, à constatação de que algumas palavras ou expressões do português brasileiro teriam origem nas línguas africanas faladas pelos escravos para cá trazidos ou nas línguas indígenas dos nativos com os quais os colonizadores conviveram.

Dessa maneira, a reviravolta no ensino, ou seja, o fato de se contar com educadores melhor preparados para lidar com as questões étnico-raciais, entre as quais o racismo, favorece a formação integral de sujeitos capazes não apenas de se reconhecerem no que aprendem/apreendem, como naquilo que da mesma forma também ensinam, dada a sua cultura extraescolar ou prévia; operando esses educadores a função de multiplicadores "de informações corretas e um fator de alteração contumaz e poderoso das situações de discriminação racial, especialmente no processo pedagógico de ensinar e aprender", diz Silva (2001, p. 70).

Como visto, a escola precisa assumir seu protagonismo de lugar de mudança e não de estigmatização. Seguindo nessa direção, certamente, estará prestando importante contribuição para que qualquer atitude, ação, comportamento cujo conteúdo ou a tônica se direcionem para a diminuição ou inferiorização de um determinado sujeito social seja imediatamente reprimido, reprovado e aquelas crianças que anualmente ingressam no sistema escolar brasileiro, público ou privado, tenham, de fato, tanto garantidas suas condições de ingresso, de permanência e de aprendizado quanto possam sentir que a escola é lugar de viver, de conviver, de ensinar, de aprender e de (re)aprender a ver o outro exatamente pelas suas diferenças, aceitando-o como é sem jamais pretender impor-lhe um dever ser.

\section{PARA ALÉM DO EU: ou como (re)aprender a ver o outro?}

Ao longo desse escrito, vem-se pontuando basicamente duas realidades existentes e manifestas no cotidiano brasileiro; tais realidades partem de constatações ou amparadas em autores 
especialistas em discussões envolvendo casos de preconceito, discriminação e racismo, incluindo-se os dispositivos legais mencionados; ou em eventos noticiados amplamente nos veículos de mídia impressa e digital sejam nacionais ou internacionais.

A primeira dessas realidades, bastante reforçada na seção inicial, evidencia que ainda que se tente evitar, ocultar ou tratar de maneira velada, o racismo está presente em falas e comportamentos, em olhares de reprovação e em tratamentos cuja intenção seja, explícita ou não, o rebaixamento social, a inferiorização de indivíduos, a negação de sua humanidade por pessoas ou grupos que se veem como superiores e isto levando-se em questão a cor da pele, quer dizer, o pertencimento étnico-racial (SILVA, 2001).

Conforme afirma Gomes (2001, p. 92), no Brasil, o racismo deve ser compreendido como

um caso complexo e singular, pois ele se afirma por meio da sua própria negação. Ele é negado de forma veemente, mas mantém-se presente no sistema de valores que regem o comportamento da nossa sociedade.

Insistir na negação do óbvio seria, como sentencia Fernandes (1972), viver imerso na fantasia de uma sociedade que aboliu a escravidão documentalmente, ou seja, como traço de formalidade civilizacional, mas que a pratica costumeiramente, naturalizando-a, como se a nobreza em abolir a submissão legal de um ser humano a outro(s) fosse, por si só, recordando-se os exemplos da intelectualidade brasileira citados por Silva (2007), capaz de perdoar a visão de mundo de que há indivíduos organizados socialmente em graus de hierarquia, estando aqueles que são negros no grau mais baixo e aí devendo permanecer.

A segunda das realidades descritas é aquela que se passa nos ambientes formais de ensino, quando, não havendo esforço do corpo docente e, em conjunto, da escola, para desenvolver práticas pedagógicas ou pedagogias de combate ao racismo, conforme propõem as DCNs da ERER (BRASIL, 2004), perpetuam-se na criança, que traz consigo das experiências extraescolares ou desenvolve no convívio com os demais colegas, essas mesmas visões de 
estranhamento negativo ao diferente, com ele não se identificando, e no mesmo sentido de negação de quem é porque se depara com manifestações de repúdio à sua imagem e ao que representa.

É como exemplifica Souza (1983, p. 34) ao apresentar falas de pessoas que sendo negras, não viam a si mesmas assim, isto é, não se enxergavam ou se reconheciam negras. Tal é o relato que a autora destaca em sua obra de um caso de rejeição ou de apagamento que por vezes limita-se à dimensão psicológica:

Meus pais, quando casaram, foram viver no interior. Era a elite da cidade: ele médico, ela professora. Fui criado nesse contexto. Não havia nenhum empenho por parte dos meus pais em reconstruir o percurso, as raízes negras de minha família. Passei minha infância aí, arrodeado daquele zelo que cerca as elites. Meus pais não me deixaram ir à escola para não me misturar com os meninos, aquela gente pobre.

Outras vezes, essa rejeição transpõe o psicológico e depositase no físico, reforçando-se uma autoimagem negativa que já vinha sendo alimentada no ambiente familiar, expandindo-se para variados locais de sociabilidade nos quais a pessoa venha a ser inserida, como se pode observar no caso descrito a seguir:

(quando era pequena) falava muito sozinha, tinha amigos invisíveis, falava muito na frente do espelho: era uma sensação de me sentir, de me reconhecer, de identidade minha. Falava comigo mesma, me achava muito feia, me identificava como uma menina negra, diferente: não tinha nenhuma menina como eu. Todas as meninas tinham o cabelo liso, o nariz fino. Minha mãe mandava eu botar pregador de roupa no nariz pra ficar menos chato. Depois eu fui sentindo que aquele negócio de olhar no espelho era uma coisa ruim. Um dia eu me percebi com medo de mim no espelho! Tive uma crise de pavor. Foi terrível. Fiquei um tempo grande assim: não podia me olhar no espelho com medo de reviver aquela sensação (SOUZA, 1983, p. 35). 
Como se vê, diante dessas constatações, caminhos que contribuam positivamente para a desconstrução desses estereótipos, estigmas ou visões negativas de humano e sociedade passam de maneira forçosa pela escola, instituição esta que se encontra na linha de frente de um processo não apenas de ensino-aprendizagem, entendendo-se por isso a preparação de indivíduos para atuarem profissionalmente, mas também local de humanização para a convivência social, para a alteridade e o respeito ao outro.

Nessa linha de pensamento, expressam-se as DCNs da ERER (BRASIL, 2004, p. 15) comentando que:

A escola tem papel preponderante para eliminação das discriminações e para emancipação dos grupos discriminados, ao proporcionar acesso aos conhecimentos científicos, a registros culturais diferenciados, à conquista de racionalidade que rege as relações sociais e raciais, a conhecimentos avançados, indispensáveis para consolidação e concerto das nações como espaços democráticos e igualitários.

Isto significa visivelmente que um dos caminhos disponíveis a ser seguido pela escola na produção de pedagogias de combate ao racismo se efetiva no conhecimento e no esclarecimento para que através desse processo se esteja estimulando o desenvolvimento de consciências críticas capazes de reconhecer situações de discriminação e preconceito, bem como mobilizarem-se unindo-se às vozes que já se levantaram em oposição à negação da humanidade de qualquer ser humano e pela igualdade, não se desprezando o importante papel que as ações afirmativas exercem para que isto se efetive. Ademais,

Para obter êxito, a escola e seus professores não podem improvisar. Têm que desfazer mentalidade racista e discriminadora secular, superando o etnocentrismo europeu, reestruturando relações étnico-raciais e sociais, desalienando processos pedagógicos. Isto não pode ficar reduzido a palavras e a raciocínios desvinculados da experiência de ser inferiorizados vivida pelos 
negros, tampouco das baixas classificações que lhe são atribuídas nas escalas de desigualdades sociais, econômicas, educativas e políticas (BRASIL, 2004, p. 15).

Uma escola comprometida com a sua função social, política e, por consequência, histórica, inserida em um regime de governo democrático não pode se permitir ser utilizada como arena de batalha, mas como campo de resolução e mediação de conflitos, sabendo-se que "ao construirmos uma política educacional que contemple a história e a real situação do povo negro, não podemos desconsiderar essa ambiguidade do racismo brasileiro", qual seja, de na sua negação residir sua afirmação (GOMES, 2001, p. 92).

Por outro lado,

como tantos outros processos de identificação, o racial é construído na relação de alteridade - nós e os outros - e em determinado contexto histórico, político e cultural. Sendo assim, ao mesmo tempo que os negros buscam a sua identidade não podem fazê-lo sem enfocar a sua diferença em relação à sociedade ou aos outros grupos sociais e instituições. Esse processo implica a tentativa de diminuir as diferenças internas do próprio grupo e a articulação em torno da reivindicação de direitos, resultando na construção de um sujeito político (GOMES, 2001, p. 92).

O que se deve perceber para avançar na efetivação de uma educação pluriétnica e multicultural que preze pelo respeito ao diferente, portanto, é justamente dar ênfase no processo educativo a uma reaprendizagem do olhar que viabilize a abertura do eu ao outro, percebendo-o e aceitando-o, de modo a se configurar uma relação de bilateralidade a qual certamente também abrirá espaço para a quebra de qualquer tendência monocultural ou inferiorizante que ainda insista em se fazer presente como resultado da ação de agentes particulares e não da visão da escola e de seus atores de maneira geral. 
Desta forma, comenta Santos (2001, p. 105-106), ao defender o programa que se vem acentuando quanto ao papel da escola na produção de pedagogias do enfrentamento,

De acordo com os Parâmetros Curriculares Nacionais (PCNs), a escola é um espaço privilegiado para a promoção da igualdade e eliminação de toda forma de discriminação e racismo, por possibilitar em seu espaço físico a convivência de pessoas com diferentes origens étnicas, culturais e religiosas. Além disso, sua atuação é intencional, sistemática, constante e obrigatória. Não podemos permanecer na definição da escola como "instrumento ideológico do Estado" ou como instrumento de "colonização" ou "aculturação". Cabe sublinhar a sua potencial responsabilidade em contribuir para a transformação dos processos de exclusão de parte da sociedade. Ela pode impulsionar uma ação cultural e política, a caminho da transformação da sociedade, por meio da transformação do indivíduo e das relações sociais.

Mas nada disso poderá se realizar a contento se além do entendimento que se tem de escola como esse espaço privilegiado para o debate e o cultivo do diálogo, seguindo-se a trilha da crítica à negação e ao velamento, e promovendo-se um ensino da exposição dos problemas sociais existentes e em evidência no país, não se lutar para que essa linguagem se torne, a longo prazo, projeto de educação nacional, pois mantendo-se limitado a algumas instituições ou regiões, certo que nestas haverá um avanço no tocante à questão do enfrentamento direto ao racismo e a toda e qualquer forma de preconceito e discriminação, esse avanço estará distante de outras realidades nas quais a prática do racismo inicia no ambiente familiar, estende-se ao escolar e retorna ao familiar e aos locais de sociabilidade em que a criança venha a ser encontrar, visto que "crianças pouco estimuladas respondem menos às propostas e aos métodos de escolarização" (ROMÃO, 2001, p. 162), e assim sendo, também responderão ou reagirão com menor ou nenhuma frequência quando se depararem com situações caracterizadas como 
racistas, sejam elas provocadoras ou vítimas desse tipo de comportamento.

Portanto, na escola, "faz-se necessário estimular esta criança para o autoconhecimento, motivando-lhe o conhecimento de sua identidade" (ROMÃO, 2001, p. 164), e isto concretizar-se-á não somente pela alusão a datas comemorativas como o 13 de maio, Dia da Abolição da Escravidão, ou 20 de novembro, Dia da Consciência Negra, mas pela garantia que os currículos escolares reflitam as realidades cotidianas vivenciadas por esses alunos, permitindo-lhes, desse modo, perceber que o conteúdo estudado contempla sua cultura, seu conhecimento prévio, suas experiências extraescolares, em resumo, seu ser social.

Um ser que não se sente oprimido, diminuído ou cuja humanidade seja negada, ao contrário, um ser cuja identidade seja constantemente afirmada no dinâmico processo de convivência social em que não há uma matriz considerada normal e outras desviantes; uma superior e outras bestializadas; uma branca e outras agrupadas na categoria de não brancas.

Por isso, qualquer transformação social que se pretenda realizar nos costumes, nos comportamentos e nas falas dos indivíduos em sociedade precisa inevitavelmente estar articulada com a escola. É para ela que devem convergir os dilemas manifestos nos sujeitos. É nela que os conflitos devem ser mediados. É dela que devem sair indivíduos dispostos sempre ao diálogo e jamais ao combate vazio, pois a partir da escola todo combate se estrutura como combate de ideias.

\section{CONSIDERAÇÕES FINAIS}

Ao longo da discussão que se seguiu, tentou-se deixar evidenciado que o famigerado mito da democracia racial brasileira é, de fato, uma armadilha ideológica criada para se sustentar a falsa ideia de que todos são iguais perante a lei, portanto, a ninguém deve ser reservado tratamento especial à luz da mesma lei.

Nota-se, por parte de quem se dispõe a defender tal prerrogativa que ou jamais foi vítima de alguma forma de preconceito e discriminação, ou se já o foi acredita tratar-se de evento isolado, 
quando os números por si só demonstram não o ser assim, quer dizer, longe vai o momento de o país aceitar-se racista e admitir que é preciso combater tal prática perversa que alude à persistência de mentalidades escravocratas ou à compreensão de que há indivíduos dignos de prestígio e de serem elevados à categoria de líderes, os brancos; e, no seu contrário, de indivíduos aos quais é reservado o lugar mais baixo na hierarquia social ainda vigente, ou seja, todos os que não são brancos.

À escola, por seu turno, compete a importante função de, estando na linha de frente do processo de formação e educação social de seus membros, abraçar a sua missão e contribuir para a produção de pedagogias e de práticas de enfrentamento ao racismo, opondo-se à aceitação das coisas como são e posicionando-se por um como deveriam ser, de onde se observa que se conseguiu chegar à possível resposta para o problema levantado e alinhado ao objetivo compartilhado em momento introdutório.

A formação e o despertar de consciências críticas somente é possível se todos os atores da educação e a sociedade civil compreenderem a urgência de se disporem a dialogar para que se alcancem os objetivos de um país, realmente, democrático e que observe os princípios da igualdade de condições e a garantia de direitos em conformidade com as particularidades de cada indivíduo.

Resta dizer que, como espaço para a mediação de conflitos e não a sua produção, e campo dialético de fomento a formas de conhecimento capazes de esclarecer e libertar, a escola possui todos os requisitos para que tais resultados sejam devidamente atingidos e todos tenham a possibilidade de se reconhecer no que aprendem, no que ensinam e desenvolver ideias transformadoras de visões ultrapassadas de humano e sociedade como ainda se percebe existirem.

\section{REFERÊNCIAS}

BRASIL. Base nacional comum curricular. Ministério da Educação, 2018b. Disponível em: http://basenacionalcomum.mec.gov.br/images/BNCC_El_EF_110518_ versaofinal_site.pdf. Acesso em: 05 mar. 2021. 
BRASIL. Constituição da República Federativa do Brasil. Brasília: Supremo Tribunal Federal, Secretaria de Documentação, 2018a. BRASIL. Diretrizes curriculares nacionais para a educação das relações étnico-raciais e para o ensino de história e cultura afrobrasileira e africana. Brasília, DF, 2004.

BRASIL. Estatuto da igualdade racial: Lei $n^{\circ} 12.288$ de julho de 2010, e legislação correlata. 4. ed. Brasília: Câmara dos Deputados, Edições Câmara, 2015.

BRASIL. LDB: Lei de diretrizes e bases da educação nacional. Brasília: Senado Federal, Coordenação de Edições Técnicas, 2017.

CARTH, J. L. A base nacional comum curricular e a aplicação de políticas de educação para educação das relações étnico-raciais (afro-brasileira, quilombola, cigana). p. 1-16. 2019. Disponível em: http://etnicoracial.mec.gov.br/images/pdf/artigos/A-BNCC2018-e-aERER.pdf. Acesso em: 05 mar. 2021.

CAVALLEIRO, E. S. Do silêncio do lar ao silêncio escolar: racismo, preconceito e discriminação na educação infantil. São Paulo: Editora Contexto, 2012.

DUBET, F. A escola e a exclusão. Cadernos de Pesquisa, n. 119, p. 29-45, jul, 2003. Disponível em:

<http://www.scielo.br/pdf/cp/n119/n119a02.pdf>. Acesso em: 05 mar. 2021.

FERNANDES, F. O negro no mundo dos brancos. São Paulo: Difusão Europeia do Livro, 1972.

FIGUEIREDO, N. M. A. (Org.). Método e metodologia na pesquisa científica. 3. ed. São Caetano do Sul, SP: Yendis Editora, 2008.

GOMES, N. L. Educação cidadã, etnia e raça: o trato pedagógico da diversidade. In: CAVALLEIRO, E. S. (Org.). Racismo e anti-racismo na educação: repensando nossa escola. 6. ed. São Paulo: Selo Negro, 2001. p. 83-96.

INEP. Censo escolar 2018: notas estatísticas. Brasília, DF: MEC, 2019. Disponível em: http://download.inep.gov.br/educacao_basica/censo_escolar/notas_ 
estatisticas/2018/notas_estatisticas_censo_escolar_2018.pdf. Acesso em: 09 mar. 2021.

JORDÃO, F. Lei que torna racismo crime completa $\mathbf{3 0}$ anos, mas ainda há muito a se fazer. Em.com.br Nacional, 05 jan. 2019. Disponível em: https://www.em.com.br/app/noticia/nacional/2019/01/05/interna_na cional,1019014/lei-que-torna-racismo-crime-completa-30-anosmas-ainda-ha-muito-a-se.shtml. Acesso em: 09 mar. 2021.

PRODANOV, C. C.; FREITAS, E. C. Metodologia do trabalho científico: métodos e técnicas de pesquisa e do trabalho acadêmico. 2. ed. Novo Hamburgo, Feevale, 2013.

RIBEIRO, M. O. et al. Desenvolvimento infantil: a criança nas diferentes etapas de sua vida. In: FUJIMORI, E.; OHARA, C. V. S. (Orgs.). Enfermagem e a saúde da criança na atenção básica. 1. ed. Barueri: Manole, 2009. p. 61-90.

RODRIGUES, P. R. S.; AQUINO, M. A. A (in)visibilidade da pessoa negra na literatura infantil: (im)possibilidades de afirmação da identidade afrodescendente na escola. Cadernos Imbondeiro. João Pessoa, v. 1, n. 1, p. 1-8, 2010. Disponível em: https://periodicos.ufpb.br/index.php/ci/article/view/13492. Acesso em: 09 mar. 2021.

ROMÃO, J. O educador, a educação e a construção de uma autoestima positiva no educando negro. In: CAVALLEIRO, E. S. (Org.).

Racismo e anti-racismo na educação: repensando nossa escola. 6. ed. São Paulo: Selo Negro, 2001. p. 161-178.

ROSSATO, C.; GESSER, V. A experiência da branquitude diante de conflitos raciais: estudos de realidades brasileiras e estadunidenses. In: CAVALLEIRO, E. S. (Org.). Racismo e anti-racismo na educação: repensando nossa escola. 6. ed. São Paulo: Selo Negro, 2001. p. 1136.

SANTOS, I. S. A responsabilidade da escola na eliminação do preconceito racial: alguns caminhos. In: CAVALLEIRO, E. S. (Org.).

Racismo e anti-racismo na educação: repensando nossa escola. 6. ed. São Paulo: Selo Negro, 2001. p. 97-113. 
SCACHETTI, A. L.; CAMILO, C. Construtivismo na prática. Nova Escola on-line, 01 ago. 2015. Disponível em:

<https://novaescola.org.br/conteudo/3428/construtivismo-napratica\#>. Acesso em: 09 mar. 2021.

SILVA, A. C. Branqueamento e branquitude: conceitos básicos na formação para a alteridade. In: NASCIMENTO, A. D.; HETKOWSKI, T. M. (Orgs.). Memória e formação de professores. Salvador: EDUFBA, 2007. p. 87-101.

SILVA, M. A. (Cidinha) da. Formação de educadores/as para o combate ao racismo: mais uma tarefa essencial. In: CAVALLEIRO, E. S. (Org.). Racismo e anti-racismo na educação: repensando nossa escola. 6. ed. São Paulo: Selo Negro, 2001. p. 65-82.

SKIDMORE, T. E. Preto no branco: raça e nacionalidade no pensamento brasileiro. 2. ed. Rio de Janeiro: Paz e Terra, 1976.

SOUZA, N. S. Tornar-se negro ou as vicissitudes da identidade do negro brasileiro em ascensão social. 2. ed. Rio de Janeiro: Edições Graal, 1983.

Submetido em: Maio/ 2020.

Aceito em: Fevereiro/ 2021. 